\title{
Integração horizontal e fragmentação partidária: uma análise de carreira política dos deputados federais da A rena em São Paulo
}

\author{
Rafael Machado Madeira*
}

\begin{abstract}
R esumo : O presente artigo visa analisar o grau de coesão partidária da Arena paulista com base no exame dos padrões de carreiras políticas das bancadas do partido na Câmara dos Deputados, nas quatro legislaturas eleitas sab o bipartidarismo. Dessa foma, aspectos como o número de migraçães partidárias, o tempo de filiação prévio à conquista de um mandato na Câmara dos Deputados e o número de cargos e de mandatos ocupados serão tomados como parâmetro para a análise. Para buscar mensurar o grau de coesão, a análise tomará como variáveis dadbs referentes às trajetórias partidárias desses parlamentares.
\end{abstract}

Palavras-chave: partidos políticos, autoritarismo, democracia, carreiras políticas.

Partidos e representação política são temas consagrados da ciência política nacional e internacional mente. D estarte, os pesquisadores que se debruçam tanto sobre os partidos tomados isoladamente, como sobre o sistema partidário como um todo vêm ganhando cada vez mais espaço no âmbito da disciplina no B rasil. TrabaIhos como os de Fleischer (1981), Lima J únior (1997), M eneguello (1998), Figueiredo e L imongi (1999) eSantos (2001) são exemplos do esforço que vem sendo feito visando a uma maior compreensão do multipartidarismo brasileiro. N esse contexto, acredita-se que a análise não apenas dos dados el eitorais ou das votações legislativas, mas também da carreira política das elites formadoras desses partidos constitui um relevante locus para um maior aprofundamento do debate acadêmico acerca desse rel evante tema. ${ }^{1}$

No entanto, analisando-se esse conjunto já significativo de obras que (independentemente

\footnotetext{
* Doutorando em Ciência Política pela UFRGS. E-mail: madeira@bol.com.br.

1. A Igumas iniciativas nesse sentido podem ser destacadas, como Rodrigues (2002) e Power (2000).
}

do ângulo de análise) visam a examinar os partidos políticos brasileiros, uma importante lacuna pode ser identificada. Em seu artigo sobre a configuração do multipartidarismo no estado do Rio de J aneiro, Schmitt (1997) aponta a falta de estudos publicados que tenham como foco central de análise a A rena. ${ }^{2}$

A fim de colaborar para o preenchimento dessa lacuna, o presente artigo tem como objetivo o exame dos dados referentes aos padrões decarreira política dos deputados federais el eitos pela A rena paulista na Câmara dos D eputados, nas quatro legislaturas empossadas ao longo do período bi partidário. Tal estudo parte da premissa de que tal exame significa uma promissora abordagem para uma maior compreensão tanto do atual sistema partidário, como de suas configurações particulares nas diferentes unidades da federação (Lima únior, 1997; Santos, 2001).

Tal análise tomará como principais variáveis aspectos como filiações anteriores, tempo de

2. As exceções encontradas são $M$ ainwuaring, M eneguello e Power (2001) e Jenks (1979), ambas iniciativas (à exceção de $M$ eneguello) de cientistas políticos norte-americanos. 
filiação antes da conquista do primeiro mandato de deputado federal e mandatos (vereador, prefeito, deputado estadual, governador etc.), cargos (secretaria municipal, estadual, ministério, presidência de estatais etc.) e funções de liderança no interior dos partidos (presidência ou vice-presidência municipal, estadual ou nacional do partido, executiva estadual ou nacional etc.) ocupados por cada parlamentar. I dentificando não só a origem partidária, mas a experiência prévia desses parlamentares e 0 tempo de convivência (isto é, a experiência político-partidária compartilhada) existente entre eles, pretende-se - entre outros aspectos mensurar o peso e a correlação de forças existentes entre as antigas organizações partidárias (período pré-64) no interior da A rena paulista.

A o se examinar a Tabela 1 a seguir, um aspecto que se destaca de forma clara é a grande heterogenei dade das bancadas formadas pela $A$ rena paul ista no que diz respei to à origem partidária de seus membros. Essa questão pode ser facilmente visual izada em função da constatação de uma acentuada fragmentação, encontrada nas bancadas arenistas paulistas em relação às antigas filiações partidárias dos seus integrantes. Essa fragmentação é comprovada pelo fato de que todos os partidos indicados na tabela têm representantes entre as bancadas federais arenistas paulistas.

Dessa forma, em São Paulo, os deputados federais arenistas têm suas respectivas origens partidárias vinculadas a não menos que nove partidos em 1974, dez em 1978, chegando a onze em 1966 e doze partidos em 1970. Somente a título de comparação, no Rio Grande do Sul (M adeira, 2003), constatou-se a presença de um mínimo de quatro organizações partidárias (1978) e um máximo de seis (1970).

Esse fato pode ser explicado pela existência, em São Paulo, de um maior número do que Sartori (1982) denomina de partidos relevantes. Nesse estado, observam-se a presença e a importância de partidos caracterizados basicamente pelo seu caráter regional (ou estadual). A ssim, agremiações partidárias como o Partido Social Progressista (PSP), de Ademar de B arros, e o Partido Trabal hista N acional (PTN) seriam dois exemplos desse fenômeno, uma vez que deviam sua força e projeção nacional basicamente às suas secções paulistas. ${ }^{3}$

Outro aspecto indicativo dessa grande heterogeneidade é a inexistência nesse estado de um partido que se destaque (como o PSD no Rio Grande do Sul ou a UDN na Bahia M adeira, 2002) como núcleo duro das bancadas arenistas paulistas entre os antigos partidos políticos. A única exceção fica por conta da presença de oito ex-udenistas em 1966, representando, mesmo assim, pouco menos que um quarto da bancada arenista paul ista el eita nesse ano. Como se verá a seguir, são os "puros" 4 que ocupam esse espaço no interior das bancadas arenistas paulistas na Câmara dos Deputados.

Essas questões devem, contudo, ser aqui interpretadas à luz da dinâmica partidária própria desse estado no regime democrático anterior, dado que grande parte das disputas interpartidárias que ocorriam entre 1946-65 foi incorporada, ou reincorporada, no seio da A rena paul ista, trazendo consigo rivalidades, leal dades e compromissos que perpassaram o interior da nova organização partidária.

0 peso dos puros: o núcleo duro das bancadas federais arenistas em São Paulo

Examinando-se inicialmente a Tabela 1, um primeiro dado que se destaca entre os demais é a presença, desde a primeira eleição, de parlamentares que iniciam suas respectivas carreiras políticas na própria A rena. Já em 1966, pode-se identificar a presença de três deputados federais arenistas sem qualquer vínculo formal com os partidos anteriormente existentes.

Além de sempre se fazerem presentes, a partir de 1970 os puros passam a constituir o grupo com maior peso em todas as legislaturas. Esse crescimento na proporção de parlamenta-

3. Para se ter uma idéia do caráter regional desses partidos, na última legislatura el eita antes da derrubada de J oão Goulart pelos militares, em 1962, nove dos 21 deputados federais do PSP provinham de São Paulo; com relação ao PTN, de um total de onze parlamentares, nove são desse estado.

4. Por "puros" designam-se todos os deputados federais arenistas que não foram formalmente filiados aos partidos anteriormente existentes, isto é, os deputados que iniciam suas respectivas carreiras políticas já sob a égide do bipartidarismo. 
res exclusivamente arenistas no conjunto das bancadas do partido na Câmara dos D eputados indica a viabilidade de trajetórias marcadas por uma rápida ascensão (ou até mesmo a viabilidade de candidatos sem trajetórias prévias) a cargos importantes, como o de deputado federal. Dessa forma, a A rena paulista caracteriza-se, a princípio, como um partido marcado pelo que Panebianco (1990) denomina como integração horizontal.

Parlamentares caracterizados pela completa ausência de carreiras prévias à conqui sta de uma cadeira na Câmara dos D eputados pela legenda arenista. Este é, como não poderia ser diferente, o perfil dos puros eleitos em 1966 (Tabela 2); além de o cargo de deputado federal marcar a estréia desses parlamentares em cargos políticos, o fato de eles manterem atividades profissionais paralelas ao mandato permite caracterizá-los como notáveis (Panebianco, 1990).
Um exemplo bastante claro desse padrão de integração horizontal é a trajetória de Edmundo M onteiro. A pós a instauração do regime militar e a instituição do sistema bipartidário, M onteiro filia-se à A rena e concorre a uma cadeira na Câmara dos D eputados por seu estado. M esmo elegendo-se em novembro de 1966, o parlamentar não interrompe suas atividades como jornalista e empresário. Esse aspecto indica o caráter secundário ocupado pela atividade político-partidária na vida do parlamentar. Hipótese esta que é reforçada pelo afastamento do parlamentar da esfera política, em virtude da não-participação em nenhuma eleição posterior, encerrando sua curta carreira política.

No que tange à trajetória político-partidária do conjunto dos puros el eitos em 1970 (Tabela 3), pode-se observar a manutenção das principais características identificadas na legislatura anterior. U m primeiro aspecto a ser levado em

Tabela 1 - Filiação aos antigos partidos: Arena - SP

\begin{tabular}{|c|c|c|c|c|c|c|c|c|c|c|c|c|c|c|c|c|c|}
\hline & ptb & mtr & Psb & ptn & psp & pdc & psd & pst & pr & prp & prt & udn & pl & are na & mdb & ni* & total \\
\hline 66 & 2 & 1 & 1 & 3 & 4 & 3 & 4 & - & - & 1 & 1 & 8 & - & 3 & - & 3 & 34 \\
\hline 70 & 1 & - & 1 & 3 & 3 & 2 & - & 1 & 1 & 1 & - & 4 & - & 7 & 3 & 6 & 33 \\
\hline 74 & - & - & 1 & - & 1 & - & - & 1 & 2 & - & 1 & 2 & - & 5 & 3 & 1 & 17 \\
\hline 78 & - & - & 1 & - & 3 & 1 & - & 1 & 2 & - & 1 & 1 & - & 7 & 3 & - & 20 \\
\hline
\end{tabular}
Fonte: Abreu, 2001.
* Partido ño ino

Tabela 2 - Trajetória política dos deputados arenistas paulistas, Arena - 1966

\begin{tabular}{|c|c|c|c|c|}
\hline Deputado & Migração & "Investimento" & № cargos & Cargos anteriores \\
\hline Edmundo Monteiro & Não & Nenhum & Nenhum & Nenhum \\
\hline Cardoso de Almeida & Não & Nenhum & Nenhum & Nenhum \\
\hline Bezerra de Melo & Não & Nenhum & Nenhum & Nenhum \\
\hline
\end{tabular}

Fonte: Abreu, 2001.

Tabela 3 - Trajetória política dos deputados arenistas paulistas, Arena - 1970

\begin{tabular}{|c|c|c|c|c|}
\hline Deputado & Migração & "Investimento" & No cargos & Cargos anteriores \\
\hline Cardoso de Almeida & Não & 4 anos & 1 & DF \\
\hline Bezerra de Melo & Não & 4 anos & 1 & DF \\
\hline Monteiro de Barros & Não & 10 anos & 2 & Secretaria Municipal (2) \\
\hline Faria Lima & Não & 4 anos & 1 & Secretaria Municipal \\
\hline Ildélio Martins & Não & Nenhum & Nenhum & Nenhum \\
\hline Orensi da Silva & Não & Nenhum & Nenhum & Nenhum \\
\hline Paulo Oliveira & Não & Nenhum & Nenhum & Nenhum \\
\hline
\end{tabular}

Fonte: Abreu, 2001. 
consideração consiste na inexperiência desses parlamentares, dado que, além de boa parte não ter nenhum tipo de vínculo com a organização partidária arenista (em 1970, a A rena tinha quatro anos, e três dos sete parlamentares não haviam exercido nenhum cargo político anterior), cinco dos sete parlamentares têm nessa legislatura suas únicas experiências em cargos eletivos.

Com relação ao pleito de 1974, a bancada eleita pela A rena paulista foi composta por cinco puros, reduzindo-se o número desses parlamentares no conjunto da bancada (Tabela 4). Cabe ressaltar, no entanto, que nessas eleições o partido governista sofre, em vários estados brasileiros, derrotas el eitorais significativas. D essa forma, a redução do número de puros não pode ser vista como um fenômeno isolado, dado que reflete e acompanha o desempenho el eitoral do partido como um todo. Pode-se, inclusive, observar que a redução atingiu mais o partido como um todo, do que esse grupo em particular.

A nalisando-se a trajetória desses parlamentares, pode-se constatar uma discreta mudança em seu perfil, uma vez que este é o primeiro grupo de puros em que se identifica algum tipo de experiência prévia, de vinculação partidária anterior à conquista de um mandato à Câmara dos Deputados. No entanto, essa mudança é ainda muito discreta para resultar em uma alteração do perfil, até aqui identificado, de carreira política entre os puros paulistas.

Com base nos dados encontrados, pode-se constatar que, assim como nas legislaturas anteriores, é marcante a presença de estreantes entre os puros eleitos pela A rena paulista à Câmara dos Deputados em 1978 (Tabela 5), constituindo sempre algo em torno da metade desse grupo. Esse aspecto indica uma grande rotatividade e renovação de deputados a cada eleição. A ssim, a heterogeneidade das trajetórias anteriores ao exercício do primeiro mandato ea falta de um maior envolvimento com a organização partidária, combinadas com essa rotatividade (ilustrada no fracasso da renovação do mandato de vários puros, o que contribuiria para formar bancadas mais experientes, e com um maior grau de coesão), contribuíram para se identificar um perfil caracterizado pelo baixo grau de coesão dos puros paulistas (padrão este significativamente diferente dos puros baianos e gaúchos - M adeira, 2002 e 2003). Por outro lado, o fato de o início das carreiras desses parlamentares dar-se em ocupações de relevância,

Tabela 4 - Trajetória política dos deputados arenistas paulistas, Arena - 1974

\begin{tabular}{|c|c|c|c|c|}
\hline Deputado & Migração & "Investimento" & No cargos & Cargos anteriores \\
\hline Cardoso Almeida & Não & 8 anos & 1 & DF (2) \\
\hline Faria Lima & Não & 8 anos & 2 & Secretaria Municipal e DF \\
\hline Paulo Franciscato & Não & 6 anos & 1 & Pref \\
\hline João de Carvalho & Não & 8 anos & Nenhum & Nenhum \\
\hline Cunha Bueno & Não & 4 anos & 1 & DE \\
\hline
\end{tabular}

Fonte: Abreu, 2001

Tabela 5- Trajetória política dos deputados arenistas paulistas, Arena - 1978

\begin{tabular}{|c|c|c|c|c|}
\hline Deputado & Migração & "Investimento" & No cargos & Cargos anteriores \\
\hline Cardoso de Almeida & Não & 12 anos & 1 & DF (3) \\
\hline Alcides Fransiscato & Não & 10 anos & 2 & Pref e DF \\
\hline Cunha Bueno & Não & 8 anos & 1 & DF (2) \\
\hline Bezerra de Melo & Não & 12 anos & 1 & DE (2) \\
\hline Caio Pompeo & Não & 8 anos & 1 & Séc Est \\
\hline Erasmo Dias & Não & 3 anos & 1 & Pref \\
\hline Francisco Rossi & Não & 6 anos & & \\
\hline
\end{tabular}

Fonte: Abreu, 2001 
como de deputado estadual e deputado federal, indica um padrão de recrutamento caracterizado pelo ingresso lateral (Santos, 2000) dos quadros arenistas, o que tenderia a dificultar a formação de bancadas mais coesas.

No entanto, ao se analisar a evolução do perfil dos puros ao longo do período, é possível constatar um aumento tanto nos vínculos prévios entre parlamentares e o partido, como na experiência prévia deles. Esse aspecto, se, por um lado, é uma conseqüência natural do "envelhecimento" do partido, por outro lado, pode ser tomado como um indicador do início de um processo de mudança no perfil dos puros eleitos pela A rena paulista à Câmara dos D eputados.

A inda com relação aos puros paulistas, um aspecto paradoxal é que, ao mesmo tempo em que a presença de parlamentares caracterizados por trajetórias relativamente curtas (perfil que vai ao encontro do que Panebianco (1990) denomina como integração horizontal), tendendo a produzir partidos relativamente mais fracos, identifica-se pelo menos um aspecto em que a presença de parlamentares com esse perfil tenderia a facilitar o processo de estruturação da nova organização partidária que estava se formando. Esse aspecto é o fato de os puros não terem incorporado, ao longo de suas respectivas trajetórias, as rivalidades e as lealdades características do antigo sistema partidário e ainda tão presentes e arraigadas entre os membros mais experientes dessa organização

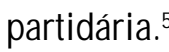

Inimigos até a véspera? Os ex-emedebistas no partido do regime em São Paulo

O utro aspecto que ilustra claramente a viabilidade de carreiras curtas e, mais do que isso, indica também a inexistência de barreiras ou fronteiras bem-definidas entre as organizações partidárias paulistas, é a manifestação de nove ocasiões em que cinco candidatos arenistas provenientes do M DB obtiveram êxito el eitoral, garantindo, assim, uma cadeira na Câmara dos Deputados.

Carreiras políticas consolidadas ao longo de, no mínimo, dez anos no interior, respectivamente, do PSD e do PTN, inclusive com passagens anteriores pela Câmara dos Deputados. Este éo perfil de A maral Furlan e C harles A marante. A pesar de terem trajetórias caracterizadas pela longevidade em seus antigos partidos no regime partidário anterior, a filiação del es à legenda oposicionista antes do ingresso à A rena caracteriza-os como exemplos de um fenômeno recorrente no estado, a migração entre os dois partidos políticos existentes no período.

A o analisar a formação do M DB em São Paulo, Melhem (1998) identifica o peso dos janistas (provindos majoritariamente do PTN e PDC) no interior do M DB. No entanto, a força desse grupo vai diminuindo gradativamente a partir do final dos anos 60 e, ao longo da década de 1970, com a contínua migração dos janistas "bons de voto" para a legenda do regime. Este éo caso de Chaves A marante. Sempre vinculado ao PTN no período anterior, ocupou nesse partido várias posições de destaque, como a presidência do diretório paulista (1859-65) e a vice-presidência do seu diretório nacional (196265). Ex-secretário estadual do Trabalho, Indústria e Comércio de São Paulo no governo Jânio Quadros (1955-1959), A marante el ege-se nesse último ano deputado estadual por seu partido, mandato que seria renovado no pleito de 1962.

Com a instauração do bipartidarismo, A marante filia-se então ao MDB, no qual se elege, em 1966, para seu primeiro mandato como

Tabela 6 - Trajetória política dos deputados arenistas paulistas, MDB - 1970

\begin{tabular}{|c|c|c|c|c|}
\hline Deputado & Migração & "Investimento" & № cargos & Cargos anteriores \\
\hline Amaral Furlan & 1 & 23 anos & 3 & Ver, DE (2) e DF (3) \\
\hline Charles Amarante & 1 & 15 anos & 2 & Sec Est (2), DE e DF \\
\hline A. Barros Filho & 1 & 4 anos & 1 & DF \\
\hline
\end{tabular}

Fonte: Abreu, 2001.

5. Como bem demonstra o testemunho de Mem de Sá, em Kinzo (1988). 
deputado federal. Logo após migrar para a A rena, A marante é convidado, em 1969, pelo então governador do estado de São Paulo, Roberto de A breu Sodré, para ocupar a Secretaria Estadual do Interior, permanecendo no cargo até abril do ano seguinte. L ogo após sua passagem pelo secretariado, o parlamentar reelegese, dessa vez pela A rena, à Câmara dos D eputados, mandato este em que o parlamentar ocupa, inclusive, a vice-liderança do partido na Câmara dos Deputados.

Em 1974, o perfil dos ex-emedebistas sofre algumas alterações (Tabela 7). No entanto, apesar da manutenção do mandato de A maral Furlan e A demar de Barros Filho, a eleição do então deputado estadual Gióia Júnior, que migrou para a A rena pouco antes desse pleito, comprova mais uma vez que, para os novos quadros arenistas, a troca de legenda não representava uma ameaça à manutenção de suas respectivas carreiras políticas.

Cabe salientar que, apesar de esse parlamentar ser filho do maior líder pessepista, ele é considerado ex-emedebista e não remanescente do PSP, dado que nunca foi filiado ao PSP. De acordo com A breu:

Sua entrada na política coincidiu com a cassação do mandato e suspensão dos direitos políticos de seu pai, em junho de 1966, quando ainda exercia o governo de São Paulo. [...] A demar de $B$ arros Filho filiou-se, na época, ao $M$ ovimento Democrático B rasileiro [...] el egendo-se deputado federal por São Paulo em novembro de 1966, com 68.575 votos. Seus suplentes na bancada eram André Franco M ontoro e M ário Covas. ${ }^{6}$ (A breu, 2001, p. 571)
A pós migrar para a legenda governista, 0 parlamentar passa a liderar parte dos remanescentes do PSP filiados à A rena paulista. Cabe salientar a existência de divisões entre os expessepistas no interior do partido governista. Em 1970, já filiado à A rena, A demar de B arros Filho reelege-se à Câmara dos Deputados. Em seu repertório biográfico, encontram-se menções bastante ilustrativas dessas divisões existentes no interior daA rena paulista, em particular, entre os remanescentes do PSP:

A segunda legislatura de A demar de Barros Filho foi marcada pelas lutas internas entre os grupos do extinto PSP pelo controle da importante base partidária que o pessepismo constituía para a A rena paulista. B arros Filho, que se considerava herdeiro político do pai, confrontava-se principal mente com o deputado federal Rafael B aldacci, mas os remanescentes do PSP dividiam-se ainda entre os grupos de Hilário Torloni, Orlando Zancaner e a "ala velha", ligada a Osvaldo de Barros. (A breu, 2001, p. 571)

A pós se reeleger novamente em 1974, 0 parlamentar assume a Secretaria Estadual do Trabalho, no governo Paulo Egídio M artins (1975-1979). Em 1978, conquista o seu quarto mandato pela bancada paulista na Câmara dos D eputados. Com a eleição de M aluf ao governo estadual, A demar de Barros Filho aproxima-se do governador, passando a apoiá-lo e levando consigo diversos remanescentes do antigo PSP. Filiando-se ao PDS, com a volta do multipartidarismo, o parlamentar candidata-se em 1982 ao Senado Federal, sendo, contudo, derrotado pelo candidato peemedebista Severo Gomes.

Tabela 7 - Trajetória política dos deputados arenistas paulistas, MDB - 1974

\begin{tabular}{|c|c|c|c|c|}
\hline Deputado & Migração & "Investimento" & № cargos & Cargos anteriores \\
\hline Amaral Furlan & 1 & 27 anos & 3 & Ver, DE (2) e DF (4) \\
\hline Gióia Júnior & 1 & 10 anos & 2 & Ver e DE \\
\hline A. Barros Filho & 1 & 8 anos & 1 & DF (2) \\
\hline
\end{tabular}

Fonte: Abreu, 2001

6. 0 mesmo ocorreu com outros pessepistas que, em protesto pela cassação dos direitos políticos de A demar de Barros, migraram para a legenda oposicionista. A ssim como A demar de Barros Filho, muitos destes acabaram por migrar para a A rena pouco tempo depois. 
A lém de A demar de Barros Filho, Gióia Júnior e $M$ aluly $N$ eto caracterizam-se pela passagem pelo MDB antes de se filiarem à legenda governista. N essa eleição, a não-constatação de nenhum novo caso de ex-emedebista recém-ingresso ao partido governista pode ser, ao menos parcialmente, explicada pelo estancamento da "hemorragia emedebista". M elhem (1998) identifica, inclusive, que, a partir desse momento, ocorre uma inversão no sentido da migração e torna-se cada vez mais claro o movimento de arenistas que passam para a legenda oposicionista, principalmentea partir da conquista do governo estadual, em 1982.

Examinando-se as trajetórias dos ex-emedebistas, um aspecto que chama a atenção é a possibilidade verificada em São Paulo de membros provenientes do $M D B$, que inclusive destacaram-se nessa legenda não só por migrarem para a A rena, mas, assim como os puros, também por se elegerem para cargos como deputado federal e ocuparem nesse partido posições de relevo. A lém desse aspecto, a mudança no sentido da migração partidária identificada por M elhem (1998) a partir de 1978 representa um indicador que vai ao encontro da caracterização dada pela literatura especializada ao sistema partidário criado pelo regime como "artificial".
Um partido catch all: a presença de dois ex-trabalhistas na A rena paulista

Outro exemplo dessa maior fluidez identificada nas fronteiras político-partidárias em São Paulo é a presença de parlamentares oriundos do antigo PTB nas bancadas arenistas paulistas. Com relação aos antigos membros desse partido, identificam-se três casos de arenistas provenientes de suas filei ras conquistando mandatos na Câmara dos Deputados.

Em 1966, na primeira eleição disputada pela A rena, dois ex-trabal histas obtiveram êxito em suas candidaturas, assegurando vaga na Câmara dos Deputados (Tabela 9). 0 primeiro deles, Celso A maral, tem uma trajetória bastante curta, iniciando em 1962 sua carreira já como deputado federal pelo PTB de São Paulo. A qui, identificase mais um caso de recrutamento lateral, uma vez que o parlamentar inicia sua carrei ra política já como deputado federal do PTB paulista. $M$ esmo filiando-se à $A$ rena e reelegendo-se em 1966, Celso A maral não chega a terminar seu mandato, em virtude da sua cassação, em fevereiro de 1969.

0 caso dos parlamentares provenientes do antigo PTB é bastante significativo, dado que permite se identificar a viabilidade de candidaturas pela A rena de políticos até então vinculados

Tabela 8 - Trajetória política dos deputados arenistas paulistas, MDB - 1978

\begin{tabular}{|c|c|c|c|c|}
\hline Deputado & Migração & "Investimento" & No cargos & Cargos anteriores \\
\hline Gióia Júnior & 1 & 14 anos & 3 & Ver, DE e DF \\
\hline A. Barros Filho & 1 & 12 anos & 1 & DF (3) \\
\hline Maluly Neto & 1 & 15 anos & 3 & Pref, DE (3) e Sec Est \\
\hline
\end{tabular}

Fonte: Abreu, 2001.

Tabela 9 - Trajetória política dos deputados arenistas paulistas, PTB - 1966

\begin{tabular}{|c|c|c|c|c|}
\hline Deputado & Migração & "Investimento" & № cargos & Cargos anteriores \\
\hline Batista Ramos & Não & 16 anos & 2 & DF (3) e Min \\
\hline Ceslo Amaral & Não & 4 anos & 1 & DF \\
\hline
\end{tabular}

Fonte: Abreu, 2001.

Tabela 10 - Trajetória política dos deputados arenistas paulistas, PTB - 1970

\begin{tabular}{|c|c|c|c|c|}
\hline Deputado & Migração & "Investimento" & № cargos & Cargos anteriores \\
\hline Batista Ramos & Não & 20 anos & 2 & DF (4) e Min \\
\hline
\end{tabular}


a um partido considerado de esquerda em nível nacional. A lém disso, permite identificar também a viabilidade de esses mesmos parlamentares ocuparem, logo após entrarem no partido governista, posições de destaque não só na Câmara dos $D$ eputados, mas também em postos importantes (como ministérios) do governo federal.

Por fim, a identificação de ex-trabal histas e ex-emedebistas nas bancadas arenistas el eitas por São Paulo à Câmara dos Deputados permite se ter uma idéia mais precisa do caráter instrumental do partido, tendo em vista que permitia, e até incentivava, candidaturas de novos arenistas com esse perfil, desde que, como afirmado anteriormente, fossem "bons de voto" (M elhem, 1998). Nesse contexto, cabia ao governo federal realizar a seleção, através da cassação de parlamentares como Celso A maral.

A UDN paulista: o peso e a relação dos arenistas e os governos militares

Como afirmado anteriormente, a UDN foi o partido que mais deputados federais forneceu à A rena paulista. A importância desse grupo está no fato de ele ter o maior contigente de parlamentares provenientes de um mesmo partido, representando $23,5 \%$ (oito em 34 ) da bancada arenista el eita em 1966 à Câmara dos Deputados. Contudo, em São Paulo, o número de parlamentares provenientes dessa organização partidária decresce rapidamente após essa primeira eleição, indicando uma perda de importância dos ex-udenistas (ao menos em suas bancadas federais).

Com relação aos ex-udenistas eleitos na legenda da A rena paulista em 1966 (Tabela 11), cabe sal ientar que uma das características mais marcantes desse conjunto de parlamentares é a longa trajetória dentro do partido anterior. Esse vínculo estável com o antigo partido pode ser facilmente verificado, pois cinco dos oito exudenistas figuram em suas fileiras desde a sua fundação. ${ }^{7}$ Dessa forma, devido ao perfil dos ex-udenistas (com carreiras marcadas pela estabilidade e longevidade no interior do antigo partido) e ao fato de esse mesmo grupo ser 0 mais numeroso no interior da bancada arenista eleita em 1966, pode-se concluir que, a exemplo do PSD gaúcho, a UDN (juntamente com o PSP) foi a "escola" política mais rel evante para os parlamentares arenistas em São Paulo.

Diferentemente do padrão de trajetórias até aqui identificado no caso paulista (rápida ascensão, carreiras curtas etc.), o grupo dos ex-udenistas caracteriza-se por uma longa trajetória no interior dessa organização. Esse aspecto é facilmente identificado, pois, além de esses cinco parlamentares integrarem a UDN paulista desde a sua fundação, eles conquistaram e exerceram cargos eletivos desde 1947. A ssim, além de

Tabela 11 - Trajetória política dos deputados arenistas paulistas, UDN - 1966

\begin{tabular}{|c|c|c|c|c|}
\hline Deputado & Migração & "Investimento" & No cargos & Cargos anteriores \\
\hline Herbert Levy & Não & 21 anos & 2 & DF (5) e Pres dir Nac \\
\hline Pereira Lopes & Não & 21 anos & 4 & Ver, Pref, DE e DF (3) \\
\hline Lauro Cruz & Não & 21 anos & 2 & Ver e DF (4) \\
\hline Ferraz Egreja & Não & 21 anos & 3 & Pref, DE e DF (2) \\
\hline Nicolau Tuma & Não & 21 anos & 2 & Ver (2) e DF (2) \\
\hline Armindo Mastrocola & Não & 8 anos & 2 & Ver e DF \\
\hline Susumu Hirata & Não & 12 anos & 2 & DE (2) e DF \\
\hline Israel Novaes & Não & 10 anos & 2 & Sec Est e DE (2) \\
\hline
\end{tabular}

Fonte: Abreu, 2001.

\footnotetext{
7. Cabe salientar aqui que Pereira Lopes (vereador e prefeito de São Carlos - SP) e Ferraz Egreja (prefeito de Ipuaçu) haviam ocupado cargos políticos ao longo da década de 1930. No entanto, apesar de serem considerados "cargo ocupado", dado que auxiliam para uma mensuração mais precisa da experiência política acumulada por esses parlamentares, o período em que eles ocuparam esses cargos não é considerado tempo de "investimento" na carreira, uma vez que não só o partido a que eram filiados mudou, como todo o sistema partidário era outro após o fim do Estado Novo.
} 
portadores de um longo vínculo com a organização partidária, quando el eitos na legenda da A rena paulista, esses parlamentares tinham também uma grande experiência no exercício de cargos el etivos em geral e, em particular, na Câmara dos Deputados.

No entanto, mesmo entre os ex-udenistas, é possível encontrar casos que corroboram a interpretação da relativa facilidade de transposição das frontei ras parti dárias no estado. Israel Novaes é um exemplo: considerado um dos principais integrantes da chamada ala renovadora da A rena, o parlamentar vota contra 0 pedido de licença para processar o então deputado emedebista Márcio M oreira Alves. Em virtude desse episódio, N ovaes teve seu mandato cassado, sem perder seus direitos políticos, em janeiro do ano seguinte. Depois da cassação, o parlamentar filia-se ao MDB, retornando à Câmara dos Deputados em 1974 (legislatura na qual chega a ocupar a vice-liderança do partido).

Com relação aos três últimos ex-udenistas encontrados na Tabela 11, pode-se observar que têm passagens relativamente rápidas pela Câmara dos D eputados. A ssim, em virtude de fracassos el eitorais ou falecimento, esses parlamentares (à exceção, é claro, de Israel N ovaes) viram interrompidas suas chances de renovar seus mandatos, caracterizando-se, dessa forma, como parlamentares com pouca experiência na Câmara dos D eputados. Porém, cabe ressaltar que as últimas três trajetórias aqui examinadas não são representativas do conjunto dos exudenistas componentes da bancada arenista eleita nas el eições de 1966.

A lém desse aspecto, cabe destacar que os três últimos mantêm laços rel ativamente fortes com a antiga organização partidária, conferindo, dessa forma, aos ex-udenistas el eitos em 1966 uma posição de destaque no conjunto da bancada, uma vez que, além de formarem o grupo mais numeroso proveniente de um mesmo partido político, eles, ao se caracterizam por extensas trajetórias dentro de uma mesma organização partidária, podem ser considerados o principal grupo dentro da bancada arenista. Essa homogeneidade nas trajetórias dos ex-udenistas pode ser tomada como o principal aspecto que contribui para um aumento do grau de coesão da bancada arenista eleita à Câmara dos D eputados em 1966.

Com relação à bancada el eita na segunda legislatura aqui analisada, 0 aspecto que mais chama a atenção em relação aos ex-udenistas é a acentuada redução do número desses parlamentares. Esse fenômeno é, ao menos em parte, explicado pela desistência de Israel Novaes, $\mathrm{N}$ icolau Tuma e Lauro Cruz em renovar seus mandatos. Já entre os que se candidataram na tentativa de renová-Io, Ferraz Egreja e A rmindo $M$ astrocola não obtiveram êxito, conquistando apenas a décima primeira e a quinta suplência, respectivamente.

$N$ ão obstante 0 fracasso el eitoral desses parlamentares, outros três ex-udenistas (Pereira Lopes, Susumu Hirata e Herbert L evy) obtiveram êxito na manutenção de seus mandatos. A ssim, apesar de reduzidos à metade, os exudenistas eleitos em 1970 (Tabela 12) podem ser caracterizados por exibirem uma experiência legisl ativa ainda maior que a do grupo el eito na legislatura anterior.

Examinando-se conjuntamente as trajetórias desses ex-udenistas, pode-se observar que eles caracterizam-se novamente não só pela experiência legislativa, mas também por trajetórias marcadas pela existência de fortes vínculos com o antigo partido, mensurados com base no longo tempo de filiação desses parlamentares à UDN paulista. A única trajetória que vai de

Tabela 12 - Trajetória política dos deputados arenistas paulistas, UDN - 1970

\begin{tabular}{|c|c|c|c|c|}
\hline Deputado & Migração & "Investimento" & № cargos & Cargos anteriores \\
\hline Herbert Levy & Não & 25 anos & 2 & DF (6) e Pres Dir Nac \\
\hline Pereira Lopes & Não & 25 anos & 4 & Ver, Pref, DE e DF (4) \\
\hline Susumo Hirata & Não & 16 anos & 2 & DE (2) e DF (2) \\
\hline Mário Teles & 2 & 16 anos & 1 & DE (3) \\
\hline
\end{tabular}

Fonte: Abreu, 2001. 
encontro a esse perfil é a de M ário Teles, que, além de exercer nessa legislatura seu primeiro e único mandato como deputado federal (ao contrário dos outros três), filia-se na UDN somente depois dejá ter sido eleito pela primeira vez deputado estadual, tendo, no máximo, sete anos como membro desse partido.

Confirmando a tendência a uma regular diminuição em seu número de membros, o grupo dos ex-udenistas el eitos em 1974 é novamente reduzido à metade (Tabela 13). A lém de marcar a manutenção da presença de Herbert Levy, que conquista pela oitava vez consecutiva um mandato na Câmara dos Deputados, a bancada arenista el eita em 1978 marca o retorno de outro ex-deputado federal, Ferraz Egreja. Por fim, 0 número de ex-udenistas que passaram pelas bancadas arenistas, bem como 0 exame de suas trajetórias, permite identificar casos que ilustram a significativa instabilidade das carreiras políticas dos arenistas paulistas.

Por fim, na última legislatura aqui examinada, confirmaram-se novamente as tendências anteriormente identificadas, uma vez que apenas um ex-udenista obtém êxito na manutenção de seu mandato: Herbert Levy (Tabela 14). Sendo um dos mais experientes deputados federais do partido, Herbert L evy é um dos poucos parlamentares arenistas caracterizados por ter uma carreira marcada pelo exercício contínuo de cargos políticos ao longo de todo o regime multipartidário (1945-1964) e do regime bi partidário, no B rasil, constituindo uma exceção entre seus colegas de partido e de bancada.

A s trajetórias dos antigos udenistas, aliadas ao peso deles na primeira bancada eleita já sob o sistema bipartidário, indicam que, além da presença de numerosos parlamentares com carreiras curtas, de rápida ascensão e com casos de migrações partidárias (inclusive do MDB para a A rena), existia no interior das bancadas arenistas paulistas um grupo de parlamentares caracterizados, ao contrário, por carreiras longas numa mesma organização partidária. Esse fato, mais a grande experiência com que a maioria dos ex-udenistas contava quando eleita sob a legenda arenista, indica a existência de um padrão de carreira diferenciado em relação ao identificado com base no exame das trajetórias dos demais deputados federais arenistas. Contudo, o padrão de carreira identificado entre os remanescentes da UDN não é suficiente para permitir qualificar o antigo partido como "a" escola política da A rena paulista (no Rio Grande do Sul e na B ahia, sim, podem-se classificar o PSD e a UDN, respectivamente, como as principais escolas políticas das A renas gaúcha e baiana).

Trajetórias heterogêneas e peso reduzido nas bancadas arenistas: os remanescentes do PSD e do PTN na Arena paulista

Com relação ao último dos três principais partidos políticos existentes no período multipartidário em nível nacional, é significativo 0 reduzido peso que os parlamentares provenientes do antigo PSD exerceram no conjunto das bancadas arenistas paulistas. Em 1966, apenas quatro, em uma bancada formada por 34 parlamentares, provinham diretamente de suas fileiras. Nas eleições subseqüentes, esse aspecto

Tabela 13 - Trajetória política dos deputados arenistas paulistas, UDN - 1974

\begin{tabular}{|c|c|c|c|c|}
\hline Deputado & Migração & "Investimento" & № cargos & Cargos ante riores \\
\hline Herbert Levy & Não & 29 anos & 2 & DF (7) e Pres. dir. Nac. \\
\hline Ferraz Egreja & Não & 29 anos & 3 & Pref, DE e DF (3) \\
\hline
\end{tabular}

Fonte: Abreu, 2001.

Tabela 14 - Trajetória política dos deputados arenistas paulistas, UDN - 1978

\begin{tabular}{|c|c|c|c|c|}
\hline Deputado & Migração & "Investimento" & № cargos & Cargos anteriores \\
\hline Herbert Levy & Não & 33 anos & 2 & DF (8) e Pres Dir Nac \\
\hline
\end{tabular}

Fonte: Abreu, 2001 
torna-se ainda mais evidente, em virtude da inexistência de parlamentares oriundos desse partido nas bancadas federais da A rena paulista.

A nalisando as carreiras políticas dos expessedistas el eitos pela $A$ rena paul ista à $C$ âmara dos D eputados (Tabela 15), observa-se que esse grupo exibe trajetórias heterogêneas. As duas primeiras são marcadas, a exemplo dos ex-udenistas, pela existência de fortes vínculos entre esses parlamentares e o partido, uma vez que eles foram membros do PSD desde sua fundação até sua extinção, em 1965. Por outro lado, a trajetória de Yukishigue Tamura é marcada por uma recorrente migração partidária, pois o parlamentar, antes de ingressar na A rena, já havia passado por três partidos no regime partidário anterior. Finalmente, o último ex-pessedista tem, diferentemente dos três primeiros que iniciaram suas carreiras no máximo até 1948 , uma trajetória bem mais curta, iniciada em 1959.

A inda com relação às trajetórias dos quatro ex-pessedistas el eitos em 1966, podem-se identificar, na cassação dos dois parlamentares, no fracasso eleitoral do terceiro e na desistência em buscar a reeleição do quarto, as causas da inexistência de parlamentares oriundos do antigo PSD nas legislaturas posteriores. No entanto, devido à importância desse partido, que no momento da criação do sistema bipartidário contava com dez deputados federais no estado (cinco dos quais ajudaram a formar a A rena paulista), a inexistência de parlamentares arenistas pertencentes a essa organização partidária mereceria um estudo à parte, que buscasse identificar as causas da ausência de remanescentes desse partido, a partir de 1970, nas bancadas arenistas el eitas à Câmara dos Deputados. U ma hipótese plausível é que, devido à migração em massa dos ex-udenistas e dos ex-pessepistas à A rena em São Paulo, os ex-pessedistas te- nham ocupado o espaço reservado ao partido oposicionista no estado. M elhem (1998) sustenta tal hipótese, ao apontar a importância dessegrupo na formação do M DB paulista.

Já com relação ao Partido Trabal hista $\mathrm{N}$ acional (PTN), identifica-se a presença de um número relativamente significativo de exmembros dessa organização no conjunto das bancadas arenistas nas duas primeiras legislaturas examinadas. Essa influência não se verifica em 1974 e 1978, quando nenhum parlamentar anteriormente pertencente a esse partido obteve êxito em eleições para a Câmara dos Deputados pela legenda arenista.

Com relação aos remanescentes do PTN paulista, 0 aspecto que mais chama a atenção em suas trajetórias é que os três foram, em al gum momento de suas carreiras, filiados a alguma outra organização partidária. Esse aspecto indica a existência de um trânsito acentuado de al guns dos principais quadros petenistas, contribuindo para uma diminuição no grau de coesão entre os remanescentes dessa antiga organização, uma vez que, pode-se supor, eles não compartilharam de uma social ização comum dentro do partido.

A pesar de terem carreiras políticas já consolidadas por no mínimo doze anos em cargos eletivos (deputado federal, em sua maioria), quando do ingresso na primeira bancada arenista eleita em 1966 à C âmara dos Deputados (Tabela 16), os remanescentes do PTN caracterizamse pela maior incidência de migração partidária no período democrático anterior. A traj etória de $R$ ui de $A$ Imeida Barbosa é emblemática nesse sentido: o parlamentar inicia a sua carreira política em 1950, ao se eleger deputado estadual pelo PTN, legislatura na qual ocupou a vicepresidência da A ssembléia L egislativa. Tendo migrado para o PTB , A Imeida B arbosa reelege-

Tabela 15 - Trajetória política dos deputados arenistas paulistas, PSD - 1966

\begin{tabular}{|c|c|c|c|c|}
\hline Deputado & Migração & "Investimento" & No cargos & Cargos anteriores \\
\hline Cunha Bueno & Não & 21 anos & 3 & DE, Sec Est e DF (2) \\
\hline Feliciano da Silva & Não & 21 anos & 4 & Ver (2), DE, Pref e DF (4) \\
\hline Yukishigue Tamura & 2 & 19 anos & 3 & Ver, DE e DF (3) \\
\hline Nazir Miguel & Não & 8 anos & 1 & Ver (2) \\
\hline
\end{tabular}

Fonte: Abreu, 2001. 
se, em 1954, ao L egislativo estadual, tornandose líder da bancada de seu (novo) partido e conquistando, inclusive, a presidência da casa. De volta ao PTN, o parlamentar reelege-se nos pleitos de 1958 e de 1962. Filiado desde 1965 à A rena, o então deputado estadual conquista, em 1966, seu primeiro mandato na Câmara dos Deputados. Reelegendo-se para seu segundo e úl timo mandato na casa, Barbosa A Imeida encerra seu mandato, deixando a Câmara em janeiro de 1975.

A pesar de contar com um número significativo de deputados federais por esse estado ao longo do período multipartidário anterior (na última legislatura, eleita em 1962, o partido tinha dez parlamentares), a presença de remanescentes do PTN é bastante discreta nas bancadas arenistas paulistas (Tabela 17). A ssim como em relação aos remanescentes do PSD, uma explicação plausível éa hipótese de que parte significativa dos antigos filiados ao partido tenha migrado para o partido oposicionista ou encontrado nesse um espaço maior de atuação. Por fim, observa-se que, assim como o perfil identificado nos ex-pessedistas, os remanescentes do PTN tinham trajetórias significativamente heterogêneas, 0 que ajuda a diminuir a coesão entre os remanescentes desse partido.
O PSP paulista: força el eitoral e marginalização política

Da mesma forma como se verificou no caso do PSD, com relação ao PSP constata-se que o número de parlamentares arenistas oriundos desse partido não corresponde à importância política exercida pelo partido no período anterior. N esse caso, porém, o paradoxo é ainda maior, uma vez que, na instauração do sistema bipartidário, por orientação do seu maior líder, A demar de Barros, a maior parte dos pessepistas migrou para o novo partido governista. Esse aspecto reflete-se no ingresso de todos os oito deputados federais pessepistas na legenda arenista em 1965. Isto é, o partido, ou pel o menos sua bancada federal, migra em peso para a nova máquina governista, migração esta que não se refletiu em uma igual representação nas bancadas federais arenistas.

A nalisando-se tais trajetórias, pode-se observar que os ex-pessepistas el eitos pela A rena paulista em 1966 eram caracterizados por uma expressiva experiência, identificada no número de cargos eletivos ocupados pelo partido ao longo do período multipartidário. A lém desse aspecto, à exceção de $\mathrm{H}$ ary Normanton, os demais parlamentares tinham longas e estáveis carreiras dentro do PSP paulista (Tabela 18).

Tabela 16 - Trajetória política dos deputados arenistas paulistas, PTN - 1966

\begin{tabular}{|c|c|c|c|c|}
\hline Deputado & Migração & "Investimento" & No cargos & Cargos anteriores \\
\hline Paulo Abreu & 1 & 16 anos & 3 & DF e Sup Sen \\
\hline Hamilton Prado & 1 & 12 anos & 4 & DF (3) \\
\hline Almeida Barbosa & 2 & 16 anos & 1 & DE (3) \\
\hline
\end{tabular}

Fonte: Abreu, 2001.

Tabela 17 - Trajetória política dos deputados arenistas paulistas, PTN - 1970

\begin{tabular}{|c|c|c|c|c|}
\hline Deputado & Migração & "Investimento" & № cargos & Cargos anteriores \\
\hline Paulo Abreu & 1 & 16 anos & 3 & DF e Sup Sen \\
\hline Almeida Barbosa & 2 & 20 anos & 2 & DE (3) e DF \\
\hline Aldo Lupo & Não & 23 anos & 1 & Sec Mun \\
\hline
\end{tabular}

Fonte: Abreu, 2001

8. Sup Sen: suplência no Senado. Paulo Abreu foi eleito pelo PTN suplente do senador Paulo Auro de Moura A ndrade e exerceu o mandato por alguns meses, em 1954, 1955 e 1959. 
Em 1970, apenas Ítalo Fittipaldi, Sílvio L opes e Cantídio Sampaio conquistam uma vaga na Câmara dos Deputados pela legenda arenista (Tabela 19). A pesar de serem apenas três expessepistas, suas carreiras corroboram a força do antigo partido e a sua caracterização como 0 partido político mais bem estruturado no estado ao longo do período democrático anterior, indicando um grau significativo de homogeneidade entre seus quadros.

Tendo atuado durante doze anos no antigo PSP, Ítalo Fittipal di iniciou sua carreira política elegendo-se vereador na capital paulista em 1954, mandato que foi renovado em 1958. A o longo desse período, Fittipaldi ocupou a Secretaria M unicipal de E ducação e Cultura, durante a gestão de A demar de B arros (1955-1959). Em 1962, Fittipaldi candidata-se pela primeira vez à Câmara dos Deputados, conquistando apenas uma suplência. A pós se filiar à A rena, conquista o seu primeiro mandato de deputado federal em 1966. Depois de se reeleger em 1970, o parlamentar tenta, sem êxito, a conquista de mais um mandato no pleito de 1974, deixando a Câmara dos D eputados no ano seguinte.
Já na bancada eleita em 1974, o fracasso eleitoral dos três parlamentares (que conquistaram apenas uma suplência) contribuiu para que a bancada eleita em 1974 fosse composta por apenas um ex-pessepista: B lota Júnior (Tabela 20). Filiado ao antigo PSB, em 1954, Blota Júnior deixa o partido, descontente com o apoio dado pel os socialistas a ânio Q uadros, filiandose ao PSP. Elegendo-se, em 1954, deputado estadual pela primeira vez já na nova legenda, Blota Júnior ocupa a vice-liderança do seu partido e da minoria na A ssembléia L egislativa do estado. N ão tendo se candidatado em 1958, B lota Júnior reel ege-se deputado estadual em 1962, ainda pelo PSP. Durante essa legislatura, o parlamentar foi o idealizador e primei ro titular da Secretaria dos N egócios do Turismo de São Paulo (1965-1966), no governo de A demar de Barros.

A pós ter sido um dos principais articuladores da candidatura A breu Sodré ao governo estadual, Blota Júnior reel ege-se, pela terceira vez, deputado estadual pela A rena paulista em 1966. Entre 1969 e 1970, B lota Júnior foi, por designação do então governador A breu Sodré, esco-

Tabela 18 - Trajetória política dos deputados arenistas paulistas, PSP - 1966

\begin{tabular}{|c|c|c|c|c|}
\hline Deputado & Migração & "Investimento" & № cargos & Cargos anteriores \\
\hline Cantídio Sampaio & Não & 19 anos & 5 & $\begin{array}{c}\text { Ver (2), DE, V Pref, DF e } \\
\text { Sec Est }\end{array}$ \\
\hline Broca Filho & Não & 19 anos & 3 & Pref, DE e DF (2) \\
\hline Ítalo Fittipaldi & Não & 12 anos & 2 & Ver (2) e Séc Mun \\
\hline Hary Normanton & 1 & 8 anos & 1 & DF (2) \\
\hline
\end{tabular}

Fonte: Abreu, 2001.

Tabela 19 - Trajetória política dos deputados arenistas paulistas, PSP - 1970

\begin{tabular}{|c|c|c|c|c|}
\hline Deputado & Migração & "Investimento" & No cargos & Cargos anteriores \\
\hline Cantídio Sampaio & Não & 23 anos & 5 & $\begin{array}{c}\text { Ver(2), DE, V Pref, } \\
\text { DF(2) e Sec Est }\end{array}$ \\
\hline Silvio Lopes & Não & 23 anos & 4 & $\begin{array}{c}\text { Ver (2), Pref (2), DE e } \\
\text { Sec Est }\end{array}$ \\
\hline Ítalo Fittipaldi & Não & 16 anos & 3 & Ver (2), Sec Mun e DF \\
\hline
\end{tabular}

Fonte: Abreu, 2001.

Tabela 20 - Trajetória política dos deputados arenistas paulistas, PSP - 1974

\begin{tabular}{|c|c|c|c|c|}
\hline Deputado & Migração & "Investimento" & № cargos & Cargos anteriores \\
\hline Blota Júnior & 1 & 20 anos & 5 & DE (3) e Séc Est \\
\hline
\end{tabular}

Fonte: Abreu, 2001. 
Ihido líder da A rena e do governo na A ssembléia L egislativa do estado. Não participando das eleições em 1970, B lotaJ únior retorna à atividade pública em 1974, elegendo-se deputado federal. A pesar de ser estreante na Câmara dos Deputados, o parlamentar atua durante essa legislatura como vice-líder da A rena e do governo do general Geisel (1974-1979). Não concorrendo à reeleição em 1978, Blota Júnior deixa a Câmara em janeiro do ano seguinte.

Finalmente, naúltima legislatura examinada, verifica-se novamente a presença de três remanescentes do antigo PSP (Tabela 21). A lém dos "veteranos" Cantídio Sampaio e Sílvio Lopes, que retornam à Câmara dos Deputados, Rui Silva el ege-se pela $A$ rena paulista à Câmara dos D eputados. Com relação à análise das traj etórias dos remanescentes do PSP e do seu peso no interior das bancadas federais eleitas pela legenda governista em São Paulo, pode-se observar que a marginal ização sofrida pelos expessepistas dentro da A rena paulista reflete-se na presença de poucos remanescentes desse partido na Câmara dos Deputados. Por outro lado, a aproximação entre $M$ aluf e os pessepistas (corporificada no acordo entre $M$ al uf e A demar de Barros Filho e no apoio maciço dos remanescentes do PSP ao candidato dissidente) garantiu aos ex-pessepistas o acesso ao governo estadual, com a vitória de Paulo M aluf em 1978.
Comparando o peso dos remanescentes da UDN ePSP, observa-se que, em ambos os partidos, ocorre uma redução constante e significativa de seus membros nas bancadas federais arenistas. Tal constatação demonstra que, mesmo tendo sido beneficiados pelo governo federal, os ex-udenistas também tiveram dificuldades na manutenção de seus espaços no interior do partido ou, ao menos, em suas bancadas federais.

PDC paulista: carreiras instáveis e vínculos precários com o partido

Final mente, o último grupo de parlamentares arenistas remanescentes de uma organização partidária existente anteriormente a ter suas trajetórias examinadas constitui o remanescente do PDC. A ssim como no caso dos remanescentes do PTN, em 1966, três arenistas anteriormente filiados ao PDC el egem-se à Câmara dos Deputados: A niz B adra, Roberto Cardoso A Ives e J osé Henrique Turner.

Integração horizontal e experiência legislativa: estas são as principais características dos remanescentes do PDC eleitos em 1966 pela A rena paulista à Câmara dos $D$ eputados (Tabela 22). 0 fato de HenriqueTurner e Cardoso $A$ Ives terem iniciado suas carreiras políticas já como deputado federal e estadual, respectivamente, é ilustrativo desse perfil encontrado na maioria dos parlamentares arenistas paulistas.

Tabela 21 - Trajetória política dos deputados arenistas paulistas, PSP - 1978

\begin{tabular}{|c|c|c|c|c|}
\hline Deputado & Migração & "Investimento" & № cargos & Cargos anteriores \\
\hline Cantídio Sampaio & Não & 31 anos & 5 & $\begin{array}{c}\text { Ver (2), DE, V Pref, } \\
\text { DF (3) e Sec Est }\end{array}$ \\
\hline Sílvio Lopes & Não & 31 anos & 5 & $\begin{array}{c}\text { Ver (2), Pref (2), DE, } \\
\text { Sec Est e DF }\end{array}$ \\
\hline Rui Silva & Não & 12 anos & 3 & Pref, DE (3) e Sec Est \\
\hline
\end{tabular}

Fonte: Abreu, 2001.

Tabela 22 - Trajetória política dos deputados arenistas paulistas, PDC - 1966

\begin{tabular}{|c|c|c|c|c|}
\hline Deputado & Migração & "Investimento" & № cargos & Cargos anteriores \\
\hline Aniz Badra & Não & 19 anos & 2 & Ver (3) e DF \\
\hline Henrique Turner & 1 & 8 anos & 1 & DF (2) \\
\hline Cardoso Alves & Não & 8 anos & 1 & DE (2) \\
\hline
\end{tabular}

Fonte: Abreu, 2001. 
Na bancada el eita em 1970 (Tabela 23), o grupo dos remanescentes do PDC mantém-se praticamente o mesmo, à exceção da ausência de Roberto Cardoso Alves (cassado). Dessa forma, pode-se observar que o grupo de expedecistas era formado por apenas dois parlamentares, A niz B adra e Henrique Turner.

Iniciando sua carreira política em 1958, quando se elegeu, pelo PSB, deputado federal por São Paulo, após ocupar a vice-liderança de seu partido na Câmara dos Deputados, Henrique Turner migra para o PDC. Em sua nova legenda, reelege-se em 1962, vindo a ocupar a viceliderança do seu novo partido. Conquistando seu terceiro e quarto mandatos em 1966 e 1970, Turner licencia-se, em fevereiro de 1967, para assumir a Secretaria Extraordinária para A ssuntos da Casa Civil do governo de São Paulo, no governo A breu Sodré (1967-1971). A pós um intervalo de quatro anos (o parlamentar não obteve êxi to na reel eição em 1974), Turner volta à Câmara dos Deputados em 1979. Tendo se filiado à legenda do PDS, Henrique Turner deixa a Câmara ainda em 1983, encerrando sua carreira política. D evido à desistência de A niz Badra em concorrer e ao fracasso eleitoral de Henrique Turner em se reeleger, em 1974 não foi encontrado na bancada arenista de São Paulo nenhum ex-pedecista. Por fim, em 1978, com a volta de H enrique Turner, a A rena passa, nova- mente, a ter em sua bancada um membro dessa antiga organização partidária.

Com poucos ex-filiados figurando entre os deputados federais da A rena paulista e com carreiras marcadas pela instabilidade e pouco tempo de filiação ao partido (à exceção de A niz $B$ adra), os remanescentes do PDC exibem um perfil muito semel hante ao dos ex-pessedistas e ex-petenistas analisados anteriormente, o que contribui ainda mais para 0 aumento da heterogeneidade identificada entre os deputados federais arenistas eleitos pelo estado de São Paulo.

O perfil dos deputados federais el eitos pela A rena paulista

A nal isando-se as trajetórias dos parlamentares eleitos pela A rena paulista à Câmara dos Deputados, ${ }^{9}$ uma das características mais importantes que pode ser destacada com relação à origem partidária deles diz respeito ao número de deputados sem vincul ação partidária anterior, ou seja, ao peso dos "puros" em cada uma das quatro legislaturas analisadas. A o contrário do observado no Rio Grande do Sul, o êxito de candidaturas de políticos exclusivamente arenistas éum traço marcante do partido em São Paulo desde a sua primeira eleição. Comprovando esse fato, na primeira eleição já é possível notar a presença dos "puros", os quais representam, nas

Tabela 23 - Trajetória política dos deputados arenistas paulistas, PDC - 1970

\begin{tabular}{|c|c|c|c|c|}
\hline Deputado & Migração & "Investimento" & No cargos & Cargos anteriores \\
\hline Aniz Badra & Não & 23 anos & 2 & Ver (3) e DF (2) \\
\hline Henrique Turner & 1 & 12 anos & 2 & DE (2) e DF \\
\hline
\end{tabular}

Fonte: Abreu, 2001.

Tabela 24-Trajetória política dos deputados arenistas paulistas, PDC- 1978

\begin{tabular}{|c|c|c|c|c|}
\hline Deputado & Migração & "Investimento" & № cargos & Cargos anteriores \\
\hline Henrique Turner & 1 & 16 & 2 & DE (2) e DF (2) \\
\hline
\end{tabular}

Fonte: Abreu, 2001.

\footnotetext{
9. Com relação aos arenistas remanescentes dos demais partidos políticos existentes no sistema partidário anterior, cabe ressaltar ainda a presença de Pedro Carolo, do antigo Partido Social Trabal hista (PST), eleito em 1970 - $1^{\circ}$ mandato na Câmara - 1974 e 1978; Diogo Nomura (1970 - 1 mandato na Câmara - 1974 e 1978) e Salvador Julianelli (1974 - $1^{\circ}$ mandato - e 1978), ambos remanescentes do Partido Republicano (PR); Ortis M onteiro, em 1966 - $5^{\circ}$ mandato - e A ntônio M arimoto, em 1978, - $1^{\circ}$ mandato - provenientes do Partido Renovador Trabalhista (PRT); M. Kertzmann, do M TR, e, por fim Plínio Salgado, eleito em 1966 - $3^{\circ}$ mandato - e 1970, do antigo Partido de Representação Popular (PRP), partido no qual foi presidente durante todo o período de vigência do multipartidarismo.
} 
três legislaturas seguintes, no mínimo cerca de um terço da bancada arenista paulista na Câmara dos Deputados.

Indo de encontro a esse perfil, os grupos formados pelos parlamentares remanescentes da UDN e do PSP são caracterizados por trajetórias marcadas pela longevidade e estabilidade em seus respectivos partidos. Representantes dos dois maiores grupos dentro das bancadas arenistas paulistas (assim como em todo 0 partido no estado), os remanescentes desses partidos são os representantes da mais profunda clivagem identificada no interior do partido governista no estado de São Paulo. E é justamente o fato de os ex-udenistas e ex-pessepistas representarem os únicos grupos em que se identificou o predomínio de trajetórias caracterizadas por um maior tempo de vinculação aos antigos partidos, aliado à histórica rivalidade entre ambos (adversários políticos durante praticamente todo o período multipartidário, 1945-1965), que dificulta a formação de um partido mais homogêneo e unificado, como era o propósito dos militares.

$B$ ancadas federais formadas por representantes de praticamente todas as cores partidárias existentes no período multipartidário anterior, com parlamentares que se caracterizam, majoritariamente, por carreiras marcadas pela rápida ascensão aos principais postos de comando (manifestado na significativa presença dos puros) e pela alta rotatividade. Esteé, em linhas gerais, o perfil dos deputados federais arenistas eleitos em São Paulo.

\section{Consider ações finais}

Com base nos dados analisados, verificouse que a existência de inúmeras facções no interior da A rena paul ista, representadas principalmente pelos ex-pessepistas, ex-udenistas e pel os "puros", sem considerar suas subdivisões internas, inviabilizou a consolidação de uma liderança no interior do partido. Em uma A rena marcada pela ausência de uma liderança estadual capaz de unir o partido e pela heterogeneidade e alta rotatividade de seus quadros, 0 estabelecimento de laços de lealdade, tanto horizontais como verticais, fica comprometido em razão do escasso tempo de socialização no interior do partido.

A análise das trajetórias dos deputados el eitos nas bancadas federais da A rena paulista confirma que este era o perfil dos principais quadros do partido em São Paulo, caracterizando-se, assim, a A rena como uma organização em que não se observava a "produção" de quadros partidários mais estáveis. E são justamente essas características que contribuíram para a ascensão de uma liderança partidária dissidente em relação ao governo federal. A escassez de víncul os entre seus quadros internos e os diretórios estadual e federal, aliada às disputas entre as diferentes facções internas pelo controle do partido, permitiram que Paulo $M$ aluf conquistasse 0 apoio, muitas vezes velado, de importantes lideranças da A rena-PDS paulista nas prévias do partido para a escolha do candidato ao governo estadual em 1978 eà Presidência da República em 1984.

0 fato de a ascensão da sua liderança darse em oposição ao governo federal, cujo controle e ingerência sobre as seções regionais da A rena durante todo o período foi uma das principais estratégias do regime para manter o domínio sobre o partido governista, só pôde ocorrer em virtude dessas características encontradas no perfil de seus quadros internos em São Paulo.

Como afirmado anteriormente, nessa conturbada rel ação entre o governo federal e o líder do PDS paulista, um dos episódios mais marcantes, além da sucessão estadual de 1978, é a vitória de Paulo $\mathrm{M}$ aluf na convenção do partido para a escolha do seu candidato à Presidência da República, em agosto de 1984. N essa convenção, M aluf, mais uma vez, derrota o candidato favorito, que contava com o apoio do Planalto, 0 então ministro M ário A ndreazza. De acordo com A breu (2001):

M esmo sem o apoio do Planal to e da maioria dos governadores eleitos com o voto popular em 1982, [M al uf] tornou-se o candidato oficial do PDS à presidência em 12 de agosto de 1984, após conquistar 493 votos na convenção partidária, contra os 350 dados à Mário A ndreazza, que logo integraria, com seu grupo, a campanha oposicionista. (A breu, 2001, p. 3508) 
Esse episódio dá uma idéia da força da liderança malufista no interior do partido, uma vez que, mesmo com a oposição aberta de grande parte das lideranças nacionais e estaduais e da maioria dos governadores do partido a sua candi datura, o líder paul ista conquista a convenção, derrotando o "candidato oficial" por uma margem significativa de votos. U m partido caracterizado por uma dinâmica de integração horizontal, pela heterogeneidade e pela existência de várias divisões internas em seus quadros - este éo perfil da A rena paulista identificado ao longo da análise. É justamente esse perfil um dos fatores que permite explicar a ascensão da liderança de Paulo M al uf, mesmo sem 0 apoio militar, e sua consolidação a partir da conquista do governo do estado. A pesar da confirmação da existência de uma forte ingerência do governo federal em relação às seções estaduais do partido, verificada no exame das sucessões estaduais, a ascensão de Paulo M aluf em São Paulo como liderança dissidente prova o caráter fal ível dessa dominação. Tal aspecto comprova também a necessidade de levar em consideração (além da atuação do governo federal) a análise do perfil dos quadros arenistas e de suas relações internas, quando se busca compreender e explicar as sucessões estaduais ao longo do período.

A análise conjunta desses fatores no processo sucessório estadual permite compreender que a estratégia utilizada pelo regime de dificultar o fortalecimento do partido e de suas lideranças em São Paulo, favorecida pelo perfil dos quadros arenistas desse estado, apesar de ter sido exitosa em quase todo o período, foi fundamental para viabilizar a ascensão da liderança de Paulo $\mathrm{M}$ al uf no interior da legenda governista. Dessa forma, a dinâmica própria ao sistema partidário paulista e as características pessoais dessa liderança (poder econômico e facilidade no contato com o el eitor paulistano) são variáveis relevantes para a explicação da ascensão e consolidação da liderança exercida por Paulo Maluf no PDS paulista, inclusive atualmente.

H eterogeneidade em seus quadros, presença de constantes e acirradas disputas internas, ausência de outras lideranças políticas capazes de capitalizar para si as inclinações da parcela mais conservadora do eleitorado paulistano e a saída de seus principais adversários no interior do partido - estas são algumas das principais características da A rena-PDS de São Paulo, que auxiliam também na explicação da ascensão e da consolidação de uma das maiores e mais polêmicas lideranças do atual PP.

A bstract: This paper aims at analyzing the degree of partisan cohesion of Arena in the State of São Paulo through the investigation of political careers pattems of Arena's blocs in the Brazilian Congress during the four legislatures elected under the two-party system. Therefore, aspects such as the number of party migrations, the time of affiliation previous to being elected in the Congress and the number of offices occupied and mandates held will be taken as parameters for the analysis. In order to measure the degree of cohesion, this analysis will take as variables data referring to the party trajectories of theses Congressmen.

K ey-words: political parties, authoritarianism, democracy, political careers.

\section{Referências}

ABREU, Alzira, BELOCH, Israel, LATTMAN WELTMAN, Fernando e LAMARÃO, Sérgio (Coords). Dicionário historico-biografico brasileiro pós-1930. Rio deJ aneiro: FGV; CPDOC, 2001.

BOWLER, Shaum, FARRELL, D avid and KATZ, Richard. Party cohesion, party discipline and parliaments. In: ___._. (Coords). Party discipline and parliamentary government. Ohio State U niversity, 1999.

FIGUEIRED O, Argelina, LIM ONGI, Fernando. Executivo e Legislativo na nova ordem constitucional. São Paulo: Ed. da FGV, 1999.

FLEISCHER, David. Os partidos políticos no Brasil. B rasília: UnB, 1981, v. 1.

JENK S, M argaret. Political parties in autoritarian Brazil. Duke U niversity: Ph.D. 1979.

KINZO, M aria D. G. O posição e autoritarismo gênese e trajetória do MDB. São Paulo: Idesp/ Vértice, 1988.

LIM A JUNIOR, Olavo B. (Org.). O sistema partidário brasileiro: diversidade e tendências, 1982/1994. Rio de J aneiro: FGV, 1997.

M ADEIRA, Rafael M achado. Arena ou Arenas? A coesão partidária da legenda do regime em três estados brasileiros. Porto A legre, 2002. Dissertação (M estrado em Ciência Política) - UFRGS, 2002. 
0 padrão de carreira política dos deputados federais da A rena baiana: trajetórias estáveis e lealdades pessoais. Revista Mediações. v. 8, n. 2, jul-dez./2003. L ondrina: Ed. UEL, 2003.

MAINWA RING, Scott, MENEGUELLO, Rachel; POWER, Timoty. Partidos conservadores no Brasil contemporâneo: quais são, o que defendem, quais são suas bases. São Paulo: Paz eTerra, 2000.

MENEGUELLO, Rachel. Partidos e governos no Brasil contemporâneo (1985-1997). São Paulo: Paz eTerra, 1998.

PANEBIANCO, Ângelo. Modelos de partido. Organización y poder en los partidos políticos. M adri: A lianza, 1990.

POWER, Timothy. The political right in postauthorian Brazil: elites, institutions and democratization: Pennsylvania State U niversity Press, 2000. RODRIGUES, Leôncio M. Partidos, ideologia e composição social: um estudo das bancadas parti- dárias na Câmara dos Deputados. São Paulo: Editora da U niversidade de São Paulo, 2002.

SA NTOS, A ndré M . Não se fazem mais oligarquias como antigamente: recrutamento parlamentar, experiência política e vínculos partidários entre os deputados brasileiros (1946 - 1998). Porto A legre, 2000. Tese (D outorado em Ciência Política) - UFGRS, 2000.

SANTOS, Fabiano (Org.). 0 poder legislativo nos estados: diversidade e convergência. São Paulo: FGV, 2001.

SARTORI, Giovani. Partidos políticos e sistemas partidários. Brasília: Ed. UnB, 1982.

SCHMITT. Rogério A. Rio de Janeiro: multipartidarismo, competitividade e realinhamento eleitoral. In: LIM A J r. Olavo B. (Org.). 0 sistema partidário brasileiro: diversidade e tendências, 1982/1994. Rio deJ aneiro: FGV, 1997. 